Barrande and the author of the article have restricted their remarks almost entirely to the trilobites, I will only ask to be allowed space to reply to the facts stated with regard to these forms of life. Trilobites have now been discovered as low down as 4,000 ft. in these red and green rocks at St. David's, that is, in the very earliest fauna known, and amongst them are forms hitherto not discovered in any other country; still if we are to believe with some that we are here near the beginning of life on the globe, or even of trilobitic life, we can expect but little evidence to support or to disprove Darwinism. For, considering the frequent changes in the sea bottom which must have taken place at this period, to produce at one time a shingle, then a sand or grit, and then a fine muddy deposit, and such beds frequently repeated, we cannot possibly expect that during all these physical changes an unbroken record of these forms should be preserved to us. No, rather we should expect to find that the necessary migrations would produce alterations in the forms, and that they should now and again return modified and altered in proportion to the time which had intervened and the circumstances which surrounded them. And this is really what we do find, and which is apparent at once to the palæontologist, who is prepared to allow and to recognise in these very marked physical changes a controlling influence capable of greatly affecting the life of the period. Again, can any one really believe, when thinking of the enormous time which must have elapsed during the accumulation of the great Laurentian series, ard possibly of other series previous and succeeding, all antecedent to the time when the Cambrian fauna made its appearance, that the seas in which these were deposited were entirely barren of life? Surely not ; therefore, why so readily jump at conclusions when there is so much room for doubt? Again, this Cambrian fauna is not without evidence in favour of evolution. Trilobites we know develope by increase of the body segments, and therefore M. Barrande says that the earliest trilobites should have the smallest number of segments in the thorax-." but that those of the primordial fauna are generally characterised by the opposite condition, while the number is less in those of the succeeding faunas." Now it does not seem to have occurred to $M$. Barrande that trilobites show every indication of having culminated at or about this period, that they had attained their maximum size and development, and that from this time they seem to have gradually diminished in size, and to have degenerated, doubtless much in the order in which they had previously progressed. This will explain also why the number of segments should, as he says, diminish in number in the genera of succeeding faunas. One of the very earliest trilobites we know of is the little Agnostus. It is also the simplest and apparently the most rudimentary of the group. It has no eyes, only two segments to the thorax, and usually an illdefined glabella. In tracing a species of Paradoxides from the earliest stage upwards, I was struck with the very great resemblance which, at an early stage, it had to the little Agnosizus. The glabella was indistinct, and much shorter in proportion to the length of the 'head than in the fully grown specimen, and the eye very faint, scarcely marked out, and the outline of the head more evenly rounded, with scarcely any indication of spines. Before the discovery of the Cambrian fauna at St. David's, no genus of trilobites had been found with four segments to the thorax, therefore we had to jump from one with two to one with six, as in Trinuclezs or Ampyou. Now, however, since the discovery of Microdiscus with four seginents, the gap has been filled up, and the genus, unforturately for those holding M. Barrande's views, appears in our earliest fauna, and where the evolu. tionist would be most inclined to look for it. It is also a most interesting and instructive genus. It is somewhat larger than Agnostus, but like it, has no eyes. The slabellar is better formed, more distinctly marked off from the cheeks, and instead of being irregularly grooved, as is usually the case with Agnostzes, it is furrowed regularly as in an advanced stage in the development of Paradoxides. In the caudal portion the axis is partly divided into segments, and in one species the lateral lobes are slightly grooved as if into rudimentary pleuræ. It is very plentiful in the beds at St. David's, and since its discovery there, species have also been found in Canacia and elsewhere.

From this stage forms have been found to rep:esent every step in development as to the number of segments, and indeed often to show marked stages in other parts. Anopolenus is really a Paradoxides with enormous eyes, reaching to the hinder margin, and with several of the hinder pleuræe consolidated together to form a large spinous pygidium. Another Paradoxides has the eyes nearly as large as Anopolcnus, but with a few more segments to the thorax, and a smaller pygidium. Other species show various gradations in the eyes and in the pygidium until we attain to $P$. Davidis, which has small eyes, a small pygidium, and the greatest number of thoracic segments. Indeed there are forms to represent almost every stage, and there can I think be no doubt that in the fauna of the Tremadoc group, which is separated from the earlier Cambrian by several thousand feet of deposits indicating a period of very shallow water in which large brachiopods and phyllopod crustaceans were the prevailing forms of life, we witness a return to very much the same conditions as existed in the earlier Cambrin periods, and with these conditions a fauna retaining a marked likeness to the earlier one, and in which the earlier types are almost reproduced, though of course greatly changed during their previous migrations. The Niobe (?) recently found in the Tremadoc rocks is truly a degraded Faradoxides, retaining the glabella and head spines, but with the rings of the thorax, excepting eight, consolidated together to form an enormous tail. Instead therefore of having here, as stated by $M$. Barrande, "a very important discord between Darwinism and facts," we find in these early faunas facts strongly favouring such a theory, and in support of evolution.

Hendon, Jan. 27

HENRY HICKS

ACCORDING to a notice in NATURE, vol. ix. p. 228, a distinguished continental maturalist finds an important discordance between Darwinisin and certain facts comnected with Trilobites and other fossil crustaceans. But his argument appears to be based on an assumption that we are acquainted with a "primordial fauna," that we are justified in dating the beginnings of life at or near some known geological period. This, however, the whole history of geology ought to make us less and less inclined to believe. It is one of those assumptions, essentially based on ignorance, on which so little dependence can rightly be placed. We have no right to call any fauna the carliest, merely because, as it happens, we know of none eartier.

A point is made of the fact that the earlier known Trilobites have more segments than the later, while individual Trilobites, as they develope, increase in number of their body segments. It may be granted at once that in this case the development of the individual is not an accurate picture of the past development of the species. But Fritz Muiller has long ago shown that we could not, on principles of Darwinism, expect it always to be so ; and surely, if Trilobites have been gradually developed rather than abruptly created, there must have been Trilobites with feiv before there were Trilobites with many segments, so that after all, the development of the individual will carry us back to an early stage in the history of the family. It could scarcely be expected to give us all the alternations and complications which that history may have presented in its whole course.

Those who on other grounds accept the theory of evolution, far from finding any obstacle to it in the large number of genera of Silurian Trilobites, will consider the largeness of that number clear evidence that life in general, and Trilobite life in particular, must have flourished on the globe for a very long period prior to the Silurian age.

The argument that we do not find connecting links between different genera has little immediate force. Ii must await the verdict of time and further investigation. Of 252 species o Trilobites, $6 \mathbf{I}$ are assigned to England. The true readins of this piece of statistics must surely be that that which great research has done for a sinall area may be equalled, and far surpassed, when as close a scrutiny is applied to the whole available surface. If no gaps between species, and genera, and orders are filled by the results of such a search, then it will be time to say that we have "an important discord between Darwinism and facts."

Torquay, Jan, 27

Thomas R. R, Stebbing

\section{Perception in Lower Animals}

I RELATE the following, as it has some bearing on a question lately ventilated in NATURE.

A friend and myselt were watching on one occasion the actions of two hali-bred Persian cais on seeing for the first time a freshly caught cubra, which had been placed in a wire-gauze cuvered box near the verandah. First of all one of the cats, a black one, stalked carefully up to the box in which the snake was keeping up a perpetual "swearing," with extended hood, and after a 